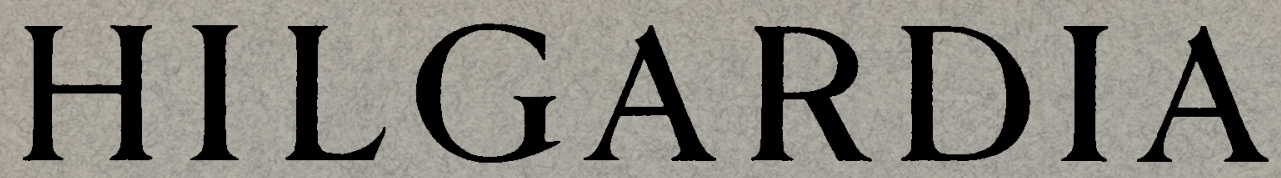

A Journal of Agricultural Science Published by the California Agricultural Experiment Station

\title{
COPPER CONTENT OF CITRUS LEAVES AND FRUIT IN RELATION TO EXANTHEMA AND FUMIGATION INJURY
} A. R. C. HAAS AND H.J.QUAYLE

\section{PHYSIOLOGICAL GRADIENTS IN CITRUS FRUITS}

A. R. C. HAAS AND L.J. KLOTZ 


\section{$\begin{array}{lllllllll}H & \text { I } & \text { L } & G & \text { A } & \text { R } & \text { D } & \text { I } & \text { A }\end{array}$}

A Journal of Agricultural Science Published by the California Agricultural Experiment Station

VoL. 9

JANUARY, 1935

No.3

\section{COPPER CONTENT OF CITRUS LEAVES AND FRUIT IN RELATION TO EXANTHEMA AND FUMIGATION INJURY ${ }^{1,2}$}

A. R. C. HAAS ${ }^{3}$ AND H. J. QUAYLE ${ }^{4}$

\section{INTRODUCTION}

A STUDY OF THE COPPER CONTENT of citrus leaves and fruit is of importance for four reasons : (1) The essential need of copper for certain plants is well known, but there is no knowledge regarding the copper content in citrus. (2) Methods frequently used to cure exanthema are the application of copper sulfate to the soil, or better still, the spraying of the entire tree with bordeaux mixture. Protection against brown rot disease is secured by spraying the lower portions of trees with bordeaux. (3) Increased and prolonged injury sometimes results when citrus trees are fumigated too soon after the application of copper. (4) An investigation of the copper content of citrus may throw some light on the cause of exanthema. This paper is concerned with the copper content of citrus in relation to these factors.

\section{PREVIOUS WORK}

It was shown by Sommer ${ }^{(37)}$ that as little as $0.06 \mathrm{mg}$ of copper per liter gave normal growth of sunflowers, tomatoes, and flax, as compared with very limited growth or death of the plant in culture solutions containing no copper. A deficiency of copper was not found to produce chlorosis. However, it was found by Anderssen ${ }^{(2)}$ that chlorosis of deciduous fruit trees was due to a copper deficiency and was cured by the use of copper applied to the soil or leaves. Lipman and MacKinney ${ }^{(25)}$ found the

1 Received for publication August 20, 1934.

2 Paper No. 314, University of California Citrus Experiment Station and Graduate School of Tropical Agriculture, Riverside, California.

3 Associate Plant Physiologist in the Experiment Station.

4 Professor of Entomology and Entomologist in the Experiment Station. 
essential need for copper by flax and barley to be primarily concerned with the ability of the plant to produce seed.

According to Allison, Bryan, and Hunter, ${ }^{(1)}$ copper sulfate and other chemicals stimulated plant response on the raw peat soils of the Florida Everglades, although the mode of action was little understood. Cook, ${ }^{(5)}$ in experiments on respiration, has shown that copper penetrates Nitella and Valonia cells almost immediately. When copper chloride was allowed to act on Aspergillus niger, there was an interval of no change, called the latent period, followed by a fall in the rate of respiration.

The function of copper in plants is so little understood that it is necessary to follow the progress of studies with copper in animals. The inability of metals other than copper to supplement iron in curing nutritutional anemia of rats was emphasized by Underhill, Orten, and Lewis ${ }^{(41)}$ as well as by Waddell, Steenbock, and Hart. ${ }^{(42)}$ The specificity of copper as a supplement to iron has received very little support from the results obtained by Myers and Beard, ${ }^{(28)}$ or by Titus, Cave, and Hughes, ${ }^{(40)}$ who found a group of substances rather than a single substance active in hemoglobin building. It is of interest that Elvehjem, Steenbock, and Hart ${ }^{(9)}$ have concluded that copper is not a constituent of the hemoglobin molecule in rat blood.

According to Elvehjem, ${ }^{(7)}$ the beneficial action of copper is not due to its functioning in the assimilation of iron, but rather to its conversion of the iron into forms which can be used for the construction of the hemoglobin molecule. The nonhemoglobin or tissue iron is considered by Josephs $^{(21)}$ as being divided into a mobile and a fixed portion. Copper influences the mobile portion in two ways : it prevents the cells that ordinarily store iron from absorbing it or causes them to give it up; or it increases the rate of hemoglobin formation by a catalytic action or decreases the rate of hemoglobin breakdown. Cunningham ${ }^{(6)}$ reported that copper feeding of rats converted inorganic to organic iron. These results obtained by feeding copper to animals serve to indicate the complexity of the role of copper in animal metabolism. Furthermore, both plant and animal nutrition investigators are aware of the minuteness of the amounts of copper that are necessary as catalysts in the normal metabolism.

The essential need of citrus for copper is of importance not only in itself, but also because of the relation of this need to the occurrence and cure of exanthema. The cause of exanthema, while considered by investigators (see Fawcett and Lee ${ }^{(11)}$ and Rhoads and DeBusk ${ }^{(33)}$ ) to be one of malnutrition, may be due to some obscure organism or to the absorption of formation of a toxin by the tree.

Floyd $^{(12)}$ and later Stevens, ${ }^{(38)}$ concluded that organic sources of 
nitrogen were related to the occurrence of the disease in Florida. Fudge ${ }^{(13)}$ found the quantity of nitrogen in the twigs of diseased trees to be three times that in healthy twigs, but found no differences in the fruit juices. Ruprecht, Camp, et al. ${ }^{(34)}$ reported an increase in all forms of nitrogen, a decrease in iron, and an increase in phosphoric acid in leaves from diseased trees. Their results resemble the analyses of mottled leaves by Kelley and Cummins ${ }^{(22)}$ and by Haas. ${ }^{(16)}$ In advanced stages of exanthema the leaves may become severely mottled. Investigations are now under way to determine the role of copper in mottle-leaf.

The theory of poor nitrifying power of soils with consequent enforced ammonia absorption by the roots as a possible cause of exanthema and mottle-leaf, was advanced by Lipman. ${ }^{(24)}$ However, exanthema-affected and mottled trees are not necessarily deficient in total nitrogen. Mottleleaf usually occurs under conditions of soil fertilization with nitrogen from any source, regardless of the nitrifying power of the soil. Mottleleaf was readily induced in soil or sand cultures $\left(\operatorname{Haas}^{(16)}\right)$ by the use of nitrogenous compounds of the urea or amino type with the enforced absorption of these poisonous compounds. Nothing is known regarding the relation of copper to such compounds in the soil or tree.

Recently, Oserkowsky and Thomas, ${ }^{(30)}$ in studies on exanthema in pears, found practically no difference in the copper content of diseased and healthy-appearing leaves from diseased trees, but found nearly twice as much copper in healthy leaves from part of the orchard free of the disease. Leaves from orchards in localities free of the disease contained about three to four times the amount of copper found in diseased leaves. The suggestion was made that exanthema in pear trees is due to a deficiency of copper. The mode of action is assumed to be the neutralization of soil toxins or the correction of a deficiency of copper.

Smith and Thomas ${ }^{(36)}$ reported the beneficial effects of copper sulfate when applied to the soil. Thomas ${ }^{(39)}$ found that the addition of copper sulfate to heavy soils was at first ineffective, but later was beneficial, and that tree injection with copper sulfate was effective. McCleery and Stokes ${ }^{(26)}$ were successful in curing exanthema of citrus by means of copper sulfate applications to the soil or by spraying the top with bordeaux.

It is of interest (Allison, Bryan, and Hunter ${ }^{(1)}$ ) that although copper sulfate gave outstanding results with plants on the Florida Everglades soil, other chemicals, such as manganese, caustic lime, or manure, also brought about considerable improvement. Orth, Wickwire, and Burge ${ }^{(29)}$ state that copper sulfate has come to be used very extensively by Florida orange growers as a remedy for "frenching." Accordingly, they treated soil with copper sulfate and found that the leaves of treated 
trees contained 4.6 times more chlorophyl than the leaves of the control trees. They concluded from this experiment that copper is necessary for chlorophyl formation.

It should be pointed out in this connection that the application of copper sulfate to the soil has long been recognized in Florida and California in the United States, and on other continents, as a remedy for exanthema, but that no one previous to Orth, Wickwire, and Burge ${ }^{(29)}$ has claimed copper sulfate as a cure for frenching (cf. Fawcett and Lee ${ }^{(11)}$ and Rhoads and DeBusk $\left.{ }^{(33)}\right)$. In fact in the early stages of exanthema, citrus leaves may be unusually green and become mottled or chlorotic generally only after a prolonged attack of exanthema. In curing such advanced stages of exanthema, therefore, with copper sulfate, mottle-leaf or chlorosis may be overcome as a stage in the disease. Ordinarily, mottle-leaf is not considered a stage of exanthema. Whether mottled leaves are deficient in copper is a question which is now being studied.

Haas ${ }^{(17)}$ was able to produce some of the symptoms of exanthema in citrus by the omission of manganese from the culture solution. In these studies, copper was not added to the culture solution; therefore, it is possible that a deficiency of copper brought about the exanthema symptoms. Experiments reported later in this paper show that this was probably the case.

It is also conceivable that iron compounds in hardpan formations which commonly underlie trees affected with exanthema may be able to precipitate the copper and manganese from the soil solution. Thus, the benefits obtained when such hardpans are broken up may be due to the continuance of an available supply of copper or manganese. The relative ease of curing exanthema in citrus with copper sulfate has prevented the use of a wide range of chemicals in attempting to cure the disease, and as a consequence very little light has been shed on the causal factors. In the case of exanthema of pears, however, zinc, manganese, and iron salts, respectively, have been found by Oserkowsky and Thomas $^{(30)}$ to be without effect on the disease.

Citrus growers, however, in districts where fumigation is practiced for scale control, have recently called attention to the need of cures for exanthema, other than by the use of copper sulfate. The fact that an increased amount of copper in soil or trees may bring about severe injury when fumigated with $\mathrm{HCN}$ was one of the reasons for determining the copper in citrus under different conditions.

Fawcett, ${ }^{(10)}$ Guba, $^{(14)}$ Butler and Jenkins, ${ }^{(4)}$ and Woglum ${ }^{(46)}$ call attention to the effects of cyanide fumigation on plants following spraying with bordeaux mixture. Guba and Holland ${ }^{(15)}$ attributed the injury 
to plants sprayed with bordeaux mixture prior to fumigation as being due to the formation of soluble copper on the foliage. In the absence of fumigation of such sprayed plants, no soluble copper was found in the water extract of the dry spray residues.

Suggestions regarding bordeaux mixture and its physiological action were published by Wilson and Runnels, ${ }^{(44)}$ who found with Coleus plants that the comparative transpiration rates of treated and untreated plants vary widely during different portions of the 24 -hour period. The treated lose much more water than the untreated plants during periods of darkness. Since fumigation is practiced during the night, the greater movement of water in the treated plants at that time may bring about an increased solubility of $\mathrm{HCN}$ in the tissue fluids, with resulting greater injury as a consequence of intracellular acidity, cell asphyxiation, or other reactions.

In a later paper, Wilson and Runnels ${ }^{(45)}$ reported that, although bordeaux mixture increased the water requirement of Coleus, tomato, and cucumber plants grown in soil kept at definite moisture contents, the combining of an oil emulsion (which when used alone decreased the transpiration rate) with the bordeaux mixture, affected the water requirement and transpiration rate but little.

In many instances the use of copper in combating citrus diseases where fumigation is practiced has led to severe injury to the trees. It would appear that copper used for such purposes is noninjurious when fumigated after an interval of three or more years, especially when the diseased trees have fully recovered. Growers frequently prefer to allow the diseased trees to go untreated unless they are assured that the use of copper followed by fumigation will not undo the good that the copper has done. At present, the injury is attributed to an increased copper content of the tree merely because copper was applied, but no data as to the increase are available. It is possible that citrus trees that consistently show a greater degree of injury to $\mathrm{HCN}$ fumigation than others may be found to contain a greater content of copper. Haas, ${ }^{(18)}$ as a result of analyses of various scale insects, ventures to suggest that red scale insects containing the least copper may be the most resistant to HCN fumigation. The purpose of the copper analyses of citrus reported in this paper is to give some basis for the consideration of problems which at present have few chemical data.

\section{SOURCE AND PREPARATION OF MATERIAL}

Chemical determinations were confined to the leaves and fruit. The marked effect of exanthema on the fruit peel, with or without the occurrence of gum pockets in the angles of the pulp segments near the core, 
made it desirable in most cases to separate the peel from the pulp. Because of the variability in the occurrence and number of seed in the fruit of the same or different varieties, it seemed desirable to discard the seed.

It was relatively easy to distinguish the diseased from the healthy fruit by the appearance of the peel and by a cross section of the pulp. The distinction between the leaves of healthy and diseased trees was often not an easy matter, even after the nature of the fruit and twigs had been taken into consideration. Consequently, healthy leaves were considered to be those taken from trees showing no twig or fruit symptoms, while diseased leaves were those taken from trees the twigs or fruit of which showed obvious symptoms of the disease.

The samples of mature citrus leaves were carefully wiped free of dust, dried at $80^{\circ} \mathrm{C}$, and finely pulverized. Fruit samples were freed of the button, wiped clean, and in most cases the peel and pulp were dried separately. The pulp halves were placed in the oven at $80^{\circ} \mathrm{C}$ on clean glass plates or large sheets of filter paper, the cut surface of the pulp being uppermost. In this way, and by having the large, roomy oven not too full of fruit at any one time, it was possible to dry out the pulp sufficiently so that it could be broken up into fragments and dried further in paper bags until suitable for pulverization.

With the method used in the determination of copper, 75 to 100 grams of dry matter gave better results than smaller size samples. The leaf and fruit samples were collected in various locations in southern California where exanthema was found to occur. ${ }^{5}$ Samples were also obtained from trees sprayed with bordeaux solution and from healthy and diseased trees growing in soil to which copper sulfate was applied.

\section{DETERMINATION OF COPPER, IRON, AND PHOSPHORUS}

Preliminary determinations of copper in citrus leaves and fruit were made by the method described by Ansbacher, Remington, and Culp, ${ }^{(3)}$ using the chromotropic reagent. The results in some cases were extremely accurate, while in others they were erratic.

The method finally employed represented a combination of portions of methods described by others. It is described in detail in order to acquaint citrus associations and other laboratories with the procedure that was used. The samples of ground dry matter were burned in silica dishes with a low flame until much of the ash was white: Silica dishes (casseroles with a deep, wide mouth and with the handle cut off) of 75-cc capacity ( $23 / 4$ inches inside diameter $\times 13 / 8$ inches deep) were used

5 The writers are indebted to Mr. Harold E. Wahlberg, Farm Advisor, Orange County, for help in securing some of the samples. 
for ashing the organic matter. Due to the bulk of the sample, several weighings were made on the analytical balance, and after the silica dish was filled, the remainder of the sample was transferred to glossy paper and was added to the dish as space was available. When the dishes were cool they were covered with watch glasses, and about 25 ce of $1: 1 \mathrm{HCl}$ were added. After digestion on the hot-plate the solution was filtered through a No. 40 Whatman filter paper into a 250-ce beaker. The cover glass, dish, and filter paper were then rinsed several times with hot water. The filter paper was transferred to the silica dish by means of a small piece of No. 40 Whatman filter paper. The dish was then dried on the hot-plate and the contents reignited until free of carbon. In most cases further ignition after filtration or the addition of nitric acid was unnecessary in order to remove all of the carbon.

After the second ignition, the dish was cooled and 25 ec of $1: 1 \mathrm{HCl}$ were added. After digestion under a cover glass on the hot-plate, filtration was again made through a No. 40 Whatman filter paper, using the original beaker and funnel. The dish was scrubbed with the addition of warm $1: 1 \mathrm{HCl}$ and thoroughly washed. The filter paper and funnel were then washed with hot water. The filter paper was folded and dried while the solution in the beaker was evaporated and the silica dehydrated in the usual manner.

When the beaker was cool, about 7.5 ce of concentrated $\mathrm{HCl}$ and some hot water were added, and the contents allowed to digest on the hot-plate. The solution was then filtered through a No. 40 Whatman filter paper into a 250-ce Erlenmeyer flask, and the precipitate carefully washed with hot water. The filter paper containing the silica, and that containing the sand and carbon, were both placed in a small platinum dish, dried, and ignited. When the dish was cool, a very small amount of water was carefully added in order to moisten and prevent the light ash from blowing away. A drop of concentrated $\mathrm{H}_{2} \mathrm{SO}_{4}$ was added and then sufficient HF to insure removal of the silica. The platinum dish was then heated on a piece of asbestos in the hood until dense, white $\mathrm{SO}_{3}$ fumes were evident. Unless the amount of silica was large, a second evaporation with a drop of concentrated $\mathrm{H}_{2} \mathrm{SO}_{4}$ and some concentrated $\mathrm{HF}$ was unnecessary. When more than one drop of concentrated $\mathrm{H}_{2} \mathrm{SO}_{4}$ is used, there is danger of spattering when the evaporation is nearly complete.

When cool, about 5 ec of $1: 1 \mathrm{HCl}$ were added to the platinum dish, which was again heated on the asbestos in the hood until the ash was dissolved. Filtration through a No. 40 Whatman paper into the Erlenmeyer flask was followed by sufficient washing with hot water to bring the volume of solution in the Erlenmeyer to about 100 ec or a known 
volume. If a 100 ce volume is used, then the solution contains approximately 10 per cent of $\mathrm{HCl}$. The acid concentration should not exceed 15 per cent by volume.

It was found that more reliable results were obtained when the silica was removed. This is in harmony with the experience of Piper, ${ }^{(32)}$ who found manganese to be more accurately determined after the removal of the silica.

$\mathrm{HCl}$ was used instead of $\mathrm{H}_{2} \mathrm{SO}_{4}$ because of the large amount of calcium present in citrus leaves and the consequent heavy precipitation of $\mathrm{CaSO}_{4}$ when $\mathrm{H}_{2} \mathrm{SO}_{4}$ is used.

The flask was heated to boiling, and a current of hydrogen sulfide was allowed to flow through a capillary glass delivery tube inserted in one hole of a two-hole rubber stopper. The delivery tube was then placed in the flask containing the boiling solution. The flow of gas was continued until the solution was cold, usually about 15 minutes being required. By means of air suction the waste $\mathrm{H}_{2} \mathrm{~S}$ was removed from the bell jar containing the Erlenmeyer flask. The drop of concentrated $\mathrm{H}_{2} \mathrm{SO}_{4}$ used in the HF volatilization of silica assures sufficient sulfur in the solution, which helps to precipitate the copper sulfide.

When the solution was cold, the stopper and capillary tube were raised out of the Erlenmeyer and washed into the flask, while the gas was still flowing. The flask was closed at once with a rubber stopper and placed in a pan of cold water or otherwise kept cool overnight, after which time the supernatant solution was clear.

The solution was then filtered through a No. 42 Whatman filter into a 250-ce beaker. The empty flask was rinsed about five times with a special wash water kept at room temperature. This wash water was distilled water acidified with acetic acid (50 to 100 ec glacial acetic acid in a liter flask of water) and saturated with hydrogen sulfide under the bell jar. The back flow of hydrogen sulfide gas from the wash water was prevented in the following manner : a short piece of rubber tubing containing a Bunsen valve-cut was closed at one end with a glass rod and was attached to the lower end of the inlet tube of the wash bottle. Finally, the filter paper was rinsed about five times with this wash water. Such washing usually was sufficient to dissolve all traces of iron and carry it into the beaker. During the filtration care should be taken to keep the copper sulfide bathed as much as possible with the wash water containing $\mathrm{H}_{2} \mathrm{~S}$ to prevent changes in the nature of the precipitate, and possible solubility changes due to too prolonged contact with the air. The filter paper containing the copper sulfide was removed from the funnel by the use of a small piece of Whatman filter paper and transferred to the Erlenmeyer flask. The top of the funnel was scrubbed 
with a small piece of the filter paper which was also added to the flask. The funnel was then rinsed with the wash water and the beaker set aside for the determination of iron.

About 10 ce or more of half concentrated $\mathrm{HNO}_{3}$ were added to the flask, which was then heated on the hot-plate in order to macerate the filter paper; the heating was continued until brown fumes were evolved. This method was found to be as efficient and less troublesome than using fuming nitric acid at the outset. The contents of the flask were diluted with hot water to a volume of 25 cc or more; otherwise, in the subsequent filtration the acid disintegrates the filter paper.

The warm contents of the flask were filtered through a No. 42 Whatman filter, the apex of which was protected with a porous platinum or platinum-alloy cone. The funnel was placed through a rubber stopper in the top of a bell jar and the funnel stem in a 150-ce, or smaller, beaker. Suction was applied at the side outlet of the bell jar. Hot water was used in washing the flask and filter paper.

Another procedure in separating the copper and iron is as follows: When the volume of sulfur and copper sulfide precipitate in the Erlenmeyer flask is extremely small, the copper sulfide may be separated from the solution by the use of a porous-bottom crucible and the copper sulfide dissolved after the removal of the iron. The nature of the precipitates obtained with citrus leaf and fruit samples generally made it very wasteful of time to use the porous-bottom crucible, even though it saved one filtration. This was especially true when 75 to 100 -gram samples of dry matter were used. Prior to being used for a second determination, such crucibles were improved by treatment with hot alkali followed by weak acid and hot water. The value of this method of cleaning the crucibles was increased when a furnace was available for the ignition and slow cooling of the crucibles, a procedure which prevented the cracking of the porous bottom.

Regardless of which of the two procedures was used for separating the copper from the solution, the subsequent procedure was as follows: The solution containing copper was evaporated barely to complete dryness on a hot-plate. Care should be taken to avoid decomposing the nitrate. Whitehead and Miller ${ }^{(43)}$ have recently reported that it is not necessary to evaporate the mineral acids completely in the iodometric determination of copper, if a small amount of $\mathrm{H}_{2} \mathrm{SO}_{4}$ is present. Time is thereby saved and the danger of forming insoluble basic cupric salts obviated. This is in agreement with details of the iodometric method described by Scott. ${ }^{(35)}$

Dilute ammonia was added to the beaker and the solution heated on the hot-plate until the odor of ammonia was faint. Five ec of glacial 
acetic acid were added to produce acidity to litmus, and the solution was boiled for about 1 minute and then cooled. Three to 4 grams of solid $\mathrm{KI}$, or its equivalent, were added, and the solution was titrated with standard thiosulfate freshly prepared by diluting $20 \mathrm{cc}$ of $0.1 \mathrm{~N}$ strength to 1 liter. One ce of this solution $(0.0020 \mathrm{~N})$ had a copper value of 0.1271 milligram. Starch solution was added, and the titration was continued from a 10-ce microburette until the end-point was reached.

In the determination of copper in soil, 100 grams of air-dry soil were treated with a mixture of $80 \mathrm{ec}$ of nitric acid and $20 \mathrm{ec}$ of sulfuric acid in a liter beaker. The mixture was heated on the hot-plate until the nitric acid fumes were removed. Repeated additions of $\mathrm{HCl}$ were made, and the evaporation was continued in order to dehydrate the silica. The copper was dissolved with 1:1 $\mathrm{HCl}$ by digestion of the silica mass on the hot-plate. With the aid of suction, the silica was separated by filtration and was volatilized as previously described. Iron in the filtrate was precipitated with ammonia, filtered with suction, and redissolved with $1: 1 \mathrm{HCl}$; it was then reprecipitated and removed by filtration. The combined filtrates from the silica and two iron filtrations were evaporated to about $100 \mathrm{ec}$ and transferred to an Erlenmeyer flask. The $\mathrm{HCl}$-soluble portion from the residue left after the silica volatilization was filtered into the flask and the acidity regulated to 10 per cent $\mathrm{HCl}$. The previously described method was then used in the precipitation and determination of the copper.

Iron and phosphate (ash) were determined in the filtrate from the copper separation by the method of Elvehjem and Hart, ${ }^{\left({ }^{8}\right)}$ the phosphate being weighed as magnesium pyrophosphate. In some cases iron was separated by the use of cupferron solution as described by Hart. ${ }^{(20)}$

\section{CHEMICAL DETERMINATIONS}

The method for the determination of copper in citrus material permits of considerable accuracy. We may cite a typical case in which a 50-gram sample of pulverized dry-leaf tissue showed 4.70 parts per million of copper in the dry matter. Another 50-gram sample of the same lot of tissue to which 5 parts per million of copper were added, showed 9.68 parts per million of copper, which indicates almost complete recovery of the added copper.

Table 1 gives the copper and iron content of citrus leaves (samples 1, 2, and 3) collected by H. S. Fawcett and H. J. Quayle at Upland on November 9, 1933. The control orange and lemon leaves were taken from adjoining groves that had never been sprayed with bordeaux. The control lemon leaves showed nearly double the copper content of the control orange leaves. A marked increase was shown in the copper con- 

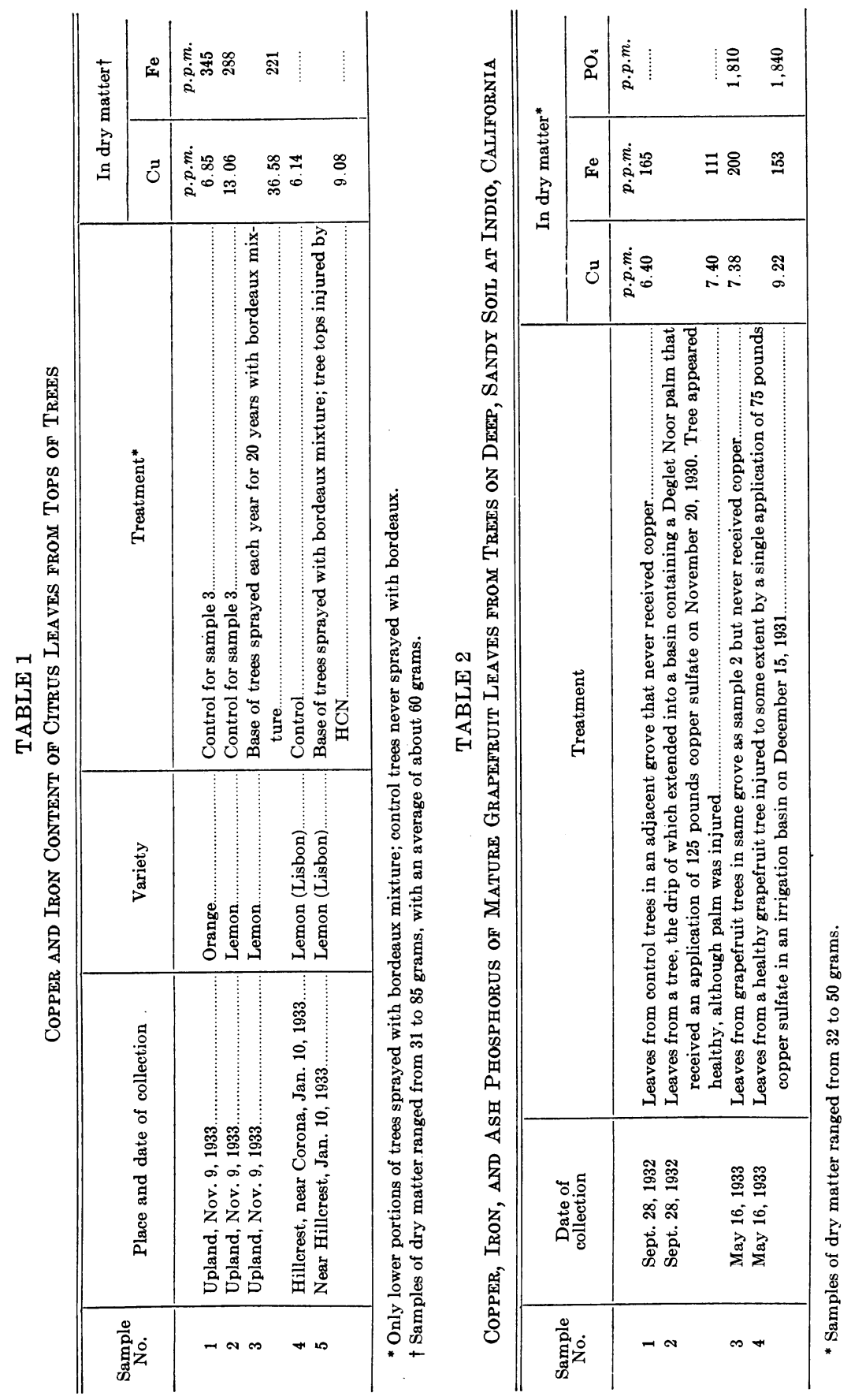
tent of the lemon leaves taken from above the sprayed portion. This would indicate an absorption of copper by the leaves of the lower portion of the tree and its translocation to leaves higher up on the tree-assuming no increased root absorption, or the unavoidable contamination of these leaves during the spraying. The increased content of copper was associated with a reduced total iron content. The lower portions of these lemon trees have been sprayed with bordeaux mixture for 20 years without injury from HCN fumigation. Since this practice has been followed for so long a period without injury to the trees, there is much likelihood that in such locations the nature of the soil may also be a factor in the injury resulting from copper.

Sample 5, consisting of leaves from the upper portion of lemon trees injured by the use of $\mathrm{HCN}$ following the application of bordeaux mixture to the lower portion of the trees, showed an increased content of copper as compared with sample 4, consisting of leaves from the upper portion of lemon trees that never received bordeaux mixture and that never showed unusual HCN injury.

The soil from the control location ${ }^{6}$ showed 14.25 parts per million of copper in the first foot, and 13.26 parts per million in the second foot; while in the location where bordeaux mixture was used, the first foot contained 14.98 parts per million and the second foot 12.75 parts per million. Samples of 100 grams of air-dried, sieved soil were used in each case. The accumulation of copper in the first foot of soil under trees that received bordeaux mixture was almost negligible.

The data in table 2 are of interest in that grapefruit leaves were available from two trees (planted March 23, 1928) growing in very sandy soil near Indio. One of the trees (sample 2) stood between the first and second palm in a row of three Deglet Noor palms and although not actually included in any one of the three irrigation basins about the palms, the grapefruit tree was so close as to have its drip and no doubt its roots included in two of the basins. Each basin received 125 pounds of copper sulfate on November 20,1930. The soil treatment severely injured the palms although they made an appreciable recovery. The grapefruit tree, as recently as February, 1934, showed no injurious effects. The second of the grapefruit trees grew in soil between two palms, the irrigation basins of which each received 75 pounds of copper sulfate on December 15, 1931. The leaf sample (sample 4) was collected on May 16, 1933, at which time some of the leaves were falling prematurely, indicating that some degree of injury had taken place.

\footnotetext{
6 Samples of soil were obtained by S. C. Dorman, of the Citrus Experiment Station, and D. A. Newcomb, of the Corona Foothill Lemon Company, near the trees from which samples 4 and 5 were collected.
} 


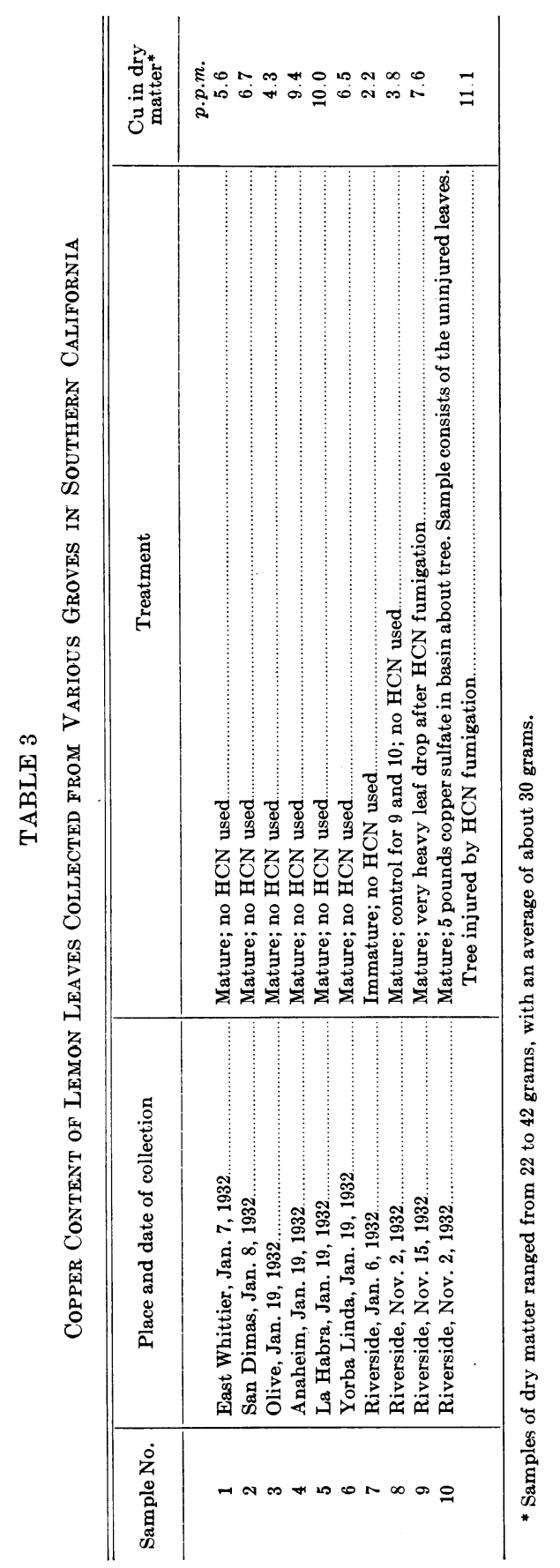


It is remarkable that the accumulation of copper was not much greater than in the control trees. The use of abundant water in the large, deep basins, together with the deep, sandy soil and the dilution factor of vigorous tree growth probably saved the trees from severe copper injury. In each case the total iron content of the dry matter was reduced when the copper content was increased. However, this does not necessarily indicate that one ion had any specific effect on the absorption of the other. The difference in the phosphorus in samples 3 and 4, without further experiments, cannot be considered significant.

The data given in table 3 were secured from analyses of samples of lemon leaves obtained from various locations. The data serve to show the relatively small concentrations of copper in lemon leaves, especially at Riverside. The data for samples 8, 9, and 10 indicate how injury resulting from fumigation in a given grove was associated with higher contents of copper. The very heavy leaf drop (sample 9) no doubt destroyed leaves with a higher copper content than those remaining on the tree after the HCN injury took place, so that the data for our sample represents the copper content of leaves at or below the threshold of injury. It is difficult to say whether or not the trees from which samples 1 to 6 were taken would have suffered from HCN fumigation because of differences in the environmental factors.

The data in table 4 (samples 1 and 2) are of interest in comparing the copper content of leaves from exanthema-affected orange trees and from adjacent healthy trees. The leaves from control trees contained nearly 15 parts per million of copper, while the leaves from exanthema-affected trees contained only about 7 parts per million. Throughout these studies, one gains the impression that exanthema on different soils and in different climatic conditions may occur when the copper content of the tree is at one level in one location and at another in another location, so that it becomes important to secure control samples as close as possible to the diseased area.

The leaves in sample 4 contained more copper than the control leaves, although most of the injured leaves had already fallen to the ground and were not included. In no case were leaves picked up from the soil because of the danger of copper contamination and of losses in the dry matter of the leaves. As a measure of precaution against splashing of soil up on to the leaves or the whipping of leaves against the soil, the leaves were picked from well up on the tree. In sample 4 had the samples been picked earlier, there is no doubt but that the copper content would have been much higher. In fact, in sample 4, the leaves were only slightly burned and may be looked upon as being just below the threshold at which severe injury took place. 


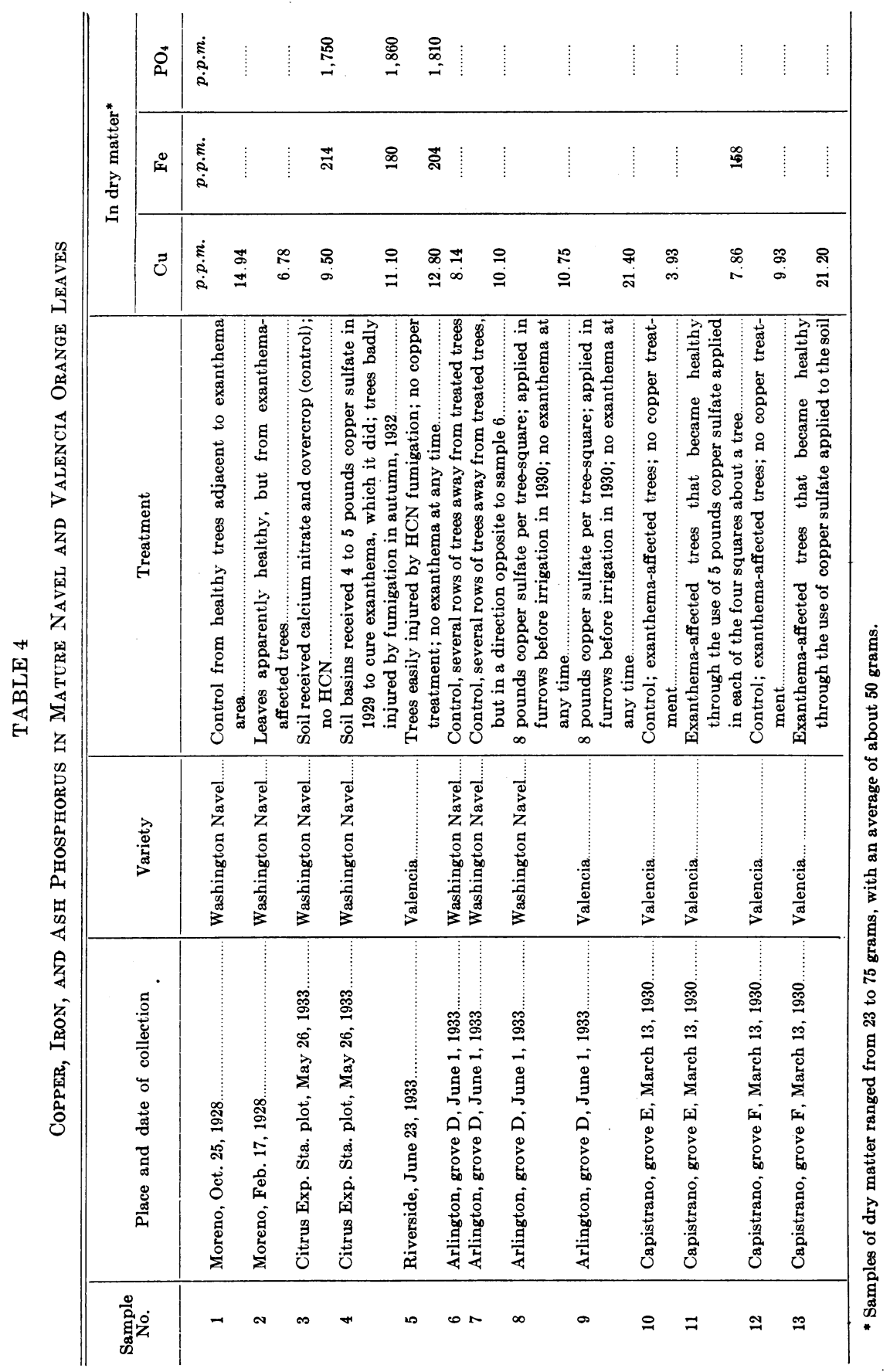


In a certain grove in Riverside, fumigation injury has been the rule for a long time with no apparent reason. Leaves (sample 5) secured from these trees showed nearly 13 parts per million of copper. Bordeaux paste and other copper preparations are frequently used in the treatment of the trunk bark diseases or for protection against their occurrence. It is possible that such applications serve to increase the supply of copper in the leaves and other portions of the tree, and later this may serve as a cause of increased fumigation injury.

It is known that copper is a very effective agent in the precipitation of proteins, and in the light of Guba and Holland's ${ }^{(15)}$ conclusion that HCN fumigation increases the solubility of copper, it is also possible that the injury resulting from fumigation of tissues rich in copper may be due to the increased precipitation of proteins in the cells. Such protein precipitation together with the action of $\mathrm{HCN}$ on tissue oxidation may determine whether tissue injury shall be reversible or permanent in nature.

While copper in contact with leaves may, according to Guba and Holland, become more soluble by $\mathrm{HCN}$ fumigation, it would appear that it is largely if not entirely the copper within the cells rather than that between the cells or on the leaf surface that determines injury. It should be mentioned in this connection that the extent of the saturation deficit of the leaf tissues may be of importance in the penetration of soluble salts into the leaves, together with solvent agencies such as composition and other properties of tissue fluids.

The possibility of an increased absorption of copper by citrus leaf tissues is seen in the use of copper sulfate in irrigation canals in order to reduce the growth of algae and thereby increase the rate of flow. In certain cases, iron sulfate was found to be effective at first, but the plants soon developed a tolerance so that copper sulfate was substituted for iron sulfate. The lumps of the sulfates were placed in gunny sacks and crushed; hence, when the sacks were immersed in the irrigation water, the finely divided material quickly dissolved and passed out in the water in such excessive amounts as to kill portions of alfalfa in a field. The effect of such water treatments on the copper content of citrus trees may be far reaching, even when the copper sulfate is carefully dripped as a solution into irrigation water in order to increase the flow or to make such water suitable for domestic use. Plants in water canals also may develop a tolerance to copper so that larger and larger amounts may be necessary as the use of copper is continued.

As shown in table 4, samples 6 to 9 inclusive were obtained from trees that were declining, but were unaffected with exanthema. Since none of the trees could be said to be in the best state of health, some were given 


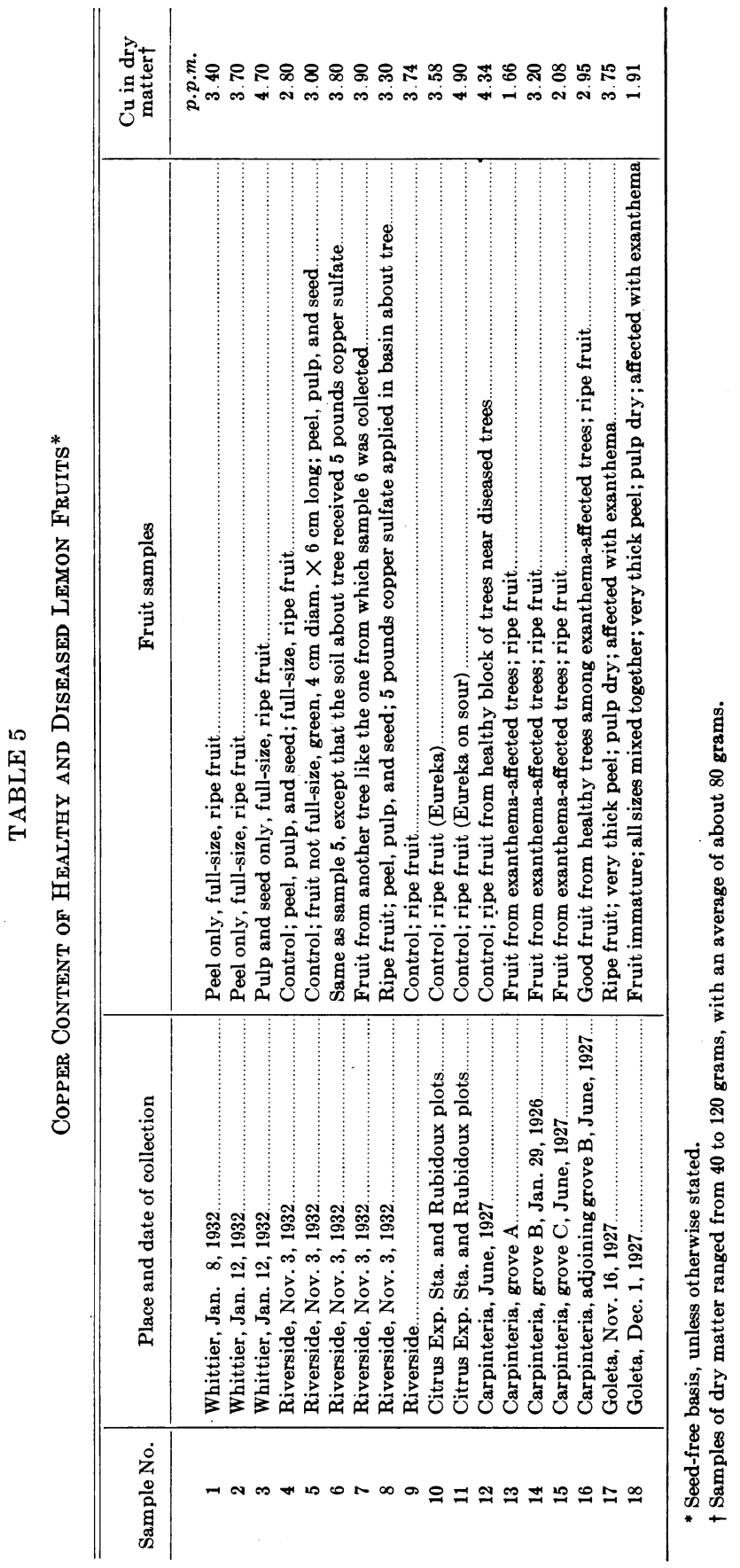


soil applications of copper sulfate to learn if it would bring about improvement. Very little increased copper content occurred in sample 8 , but in sample 9 the increase was about equal to the original content.

The leaves (sample 10) from one grove of exanthema-affected trees on very heavy, black soil at Capistrano showed about 4 parts per million of copper, while those (sample 11) from trees in the same area that

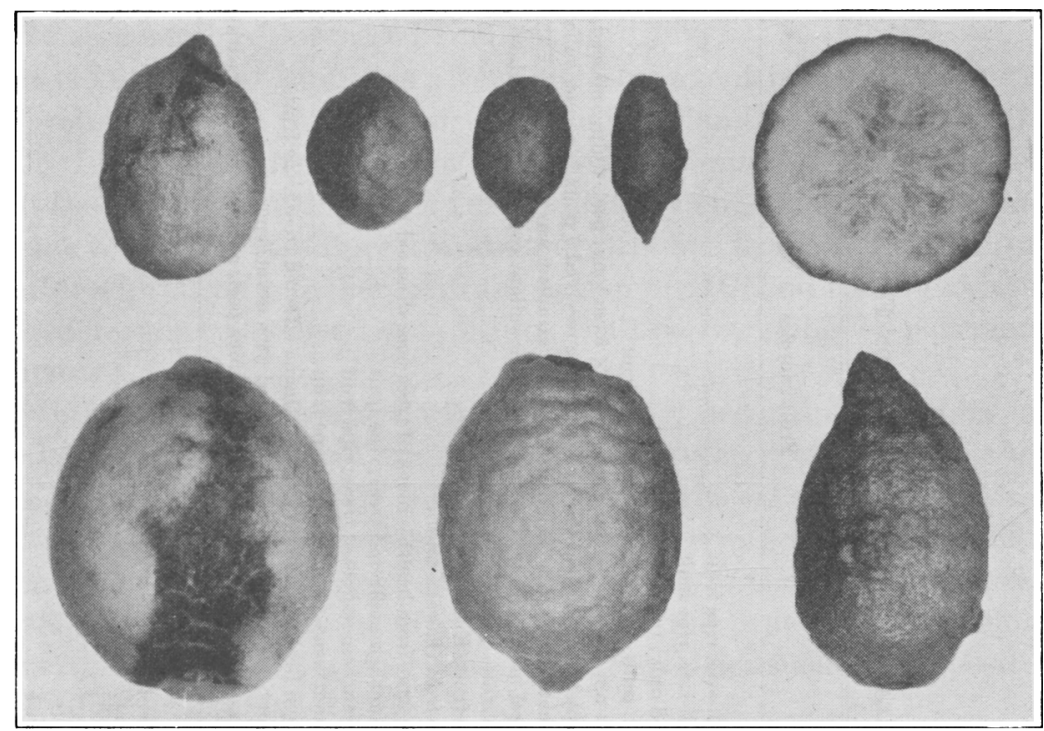

Fig. 1.-Lemon fruits (sample 18, table 5) affected with exanthema. The fruits were irregular in shape and topography. The rind was scaly from cracked, gum-soaked areas, and was very thick, while the pulp was dry and worthless.

were made healthy by the application of copper sulfate to the soil, contained nearly double this amount of copper.

In another grove at Capistrano the leaves (sample 12) from exanthema-affected trees contained nearly 10 parts per million of copper, while those (sample 13) from diseased trees that were made healthy by the application of copper sulfate to the soil, contained about double this amount. Samples 10 to 13 illustrate the variation in the copper content of leaves from diseased trees in groves a few miles distant from each other. Table 4 (samples 3 and 4 ) again shows the reduced iron and increased phosphate in cases where copper has brought the trees back to health.

Table 5 gives the copper content of healthy and diseased lemon fruit. In each case at least 25 lemons were used in preparing the fresh samples from the dry matter of which an aliquot was taken for the copper determination. Table 5 indicates the relatively small concentration of 


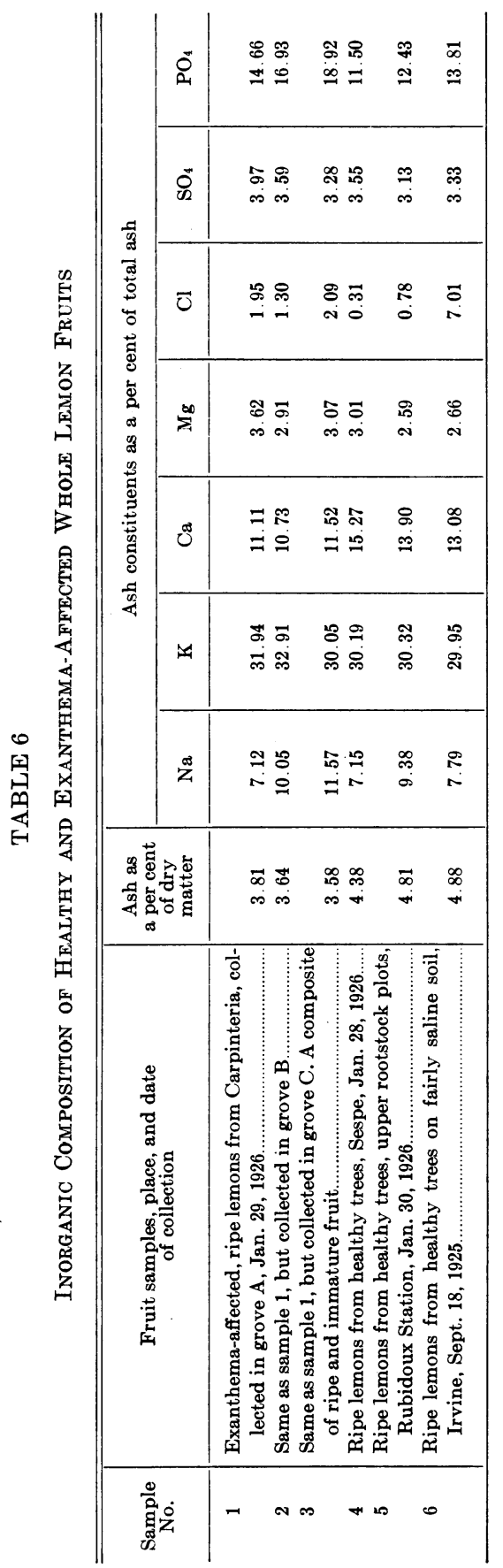


copper in lemon fruit. The application of copper sulfate to the soil (samples 6 to 8 ) is reflected but slightly in the copper content of the fruit.

The importance of copper for fruit affected with exanthema is seen in samples 12 to 18 inclusive. No control other than sample 12 was available for samples 17 and 18. Figure 1 illustrates the condition of lemons (sample 18) when affected with exanthema. The fruit is abnormally shaped and the peel is thick and irregular in topography.

TABLE 7

Copper Content of Healthy Washington Navel and Valencia Oranges

\begin{tabular}{|c|c|c|c|}
\hline $\begin{array}{l}\text { Sample } \\
\text { No. }\end{array}$ & Place and date of collection & Fruit samples & $\begin{array}{c}\text { Cu in dry } \\
\text { matter* }\end{array}$ \\
\hline 1 & Highland, Feb. 24, 1928 & Navel; whole fruit; trees in poor condi- & p.p.m. \\
\hline 2 & Moreno, Oct. 25, $1927 \ldots \ldots$ & Navel; whole fruit; trees in good condi- & 2.77 \\
\hline 3 & Highland, May $3,1927 \ldots$ & $\begin{array}{l}\text { tion } \\
\text { Valencia; peel and pulp; trees in poor }\end{array}$ & 4.36 \\
\hline 4 & Highland, May $3,1927 \ldots$ & $\begin{array}{c}\text { condition. } \\
\text { Valencia; peel and pulp; Tahiti sweet }\end{array}$ & 1.78 \\
\hline 5 & Riverside, plot F, Rubidoux, Jan. 31, & $\begin{array}{l}\text { orange root, lemon trunk } \\
\text { Valencia; peel and pulp }\end{array}$ & $\begin{array}{l}2.22 \\
3.28\end{array}$ \\
\hline 6 & $\begin{array}{l}\text { Riverside, plots } N \text { and F, Rubidoux, } \\
\text { Dec. } 27,1926 .\end{array}$ & 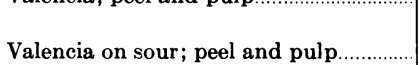 & 2.56 \\
\hline 7 & Riverside, Rubidoux, Dec. 27, 1926........ & $\begin{array}{l}\text { Valencia on sweet; peel and pulp; upper } \\
\text { rootstock }\end{array}$ & 3.02 \\
\hline 8 & Riverside, Rubidoux, Dec. 27, 1926....... & $\begin{array}{l}\text { Valencia on Trifoliate orange; peel and } \\
\text { pulp; upper rootstock. }\end{array}$ & 2.27 \\
\hline
\end{tabular}

* Samples of dry matter range from 60 to 112 grams, with an average of about 105 grams.

Table 5 suggests, although it does not show conclusively, that there may be a range for a given location of diseased trees below which the copper content of the fruit may not fall without showing symptoms of the disease. In addition, it was found that the total iron content of the dry matter of sample 9 was 35 parts per million and of sample 10, 26 parts per million.

It may be of interest to consider the results (table 6 ) of analyses of healthy and exanthema-affected lemon fruits. One outstanding difference lies in the ash content of the dry matter, which is much greater in healthy fruit. It has been found that the ash of diseased fruit contains slightly less calcium, but more phosphate than that of healthy fruit. On a dry weight basis the $\mathrm{PO}_{4}$ content of the two groups of samples, namely, diseased and healthy, varies within the same range. A further comparison on a dry-weight basis shows a larger percentage of potassium and more calcium in the fruits from the healthy trees as compared with the fruits from diseased trees. 
The results of preliminary copper determinations of healthy Washington Navel and Valencia oranges are given in table 7. The lowest copper content was 1.78 parts per million in sample 3 from Highland, and the highest was 4.36 parts per million in sample 2 from Moreno. The iron content of sample 1 was 68 parts per million. The data emphasize the need of a greater degree of subdivision of the fruit because of the small concentrations of copper involved. Division of the fruit into

TABLE 8

Copper Content of Peel and Pulp of Healthy Valencia Oranges*

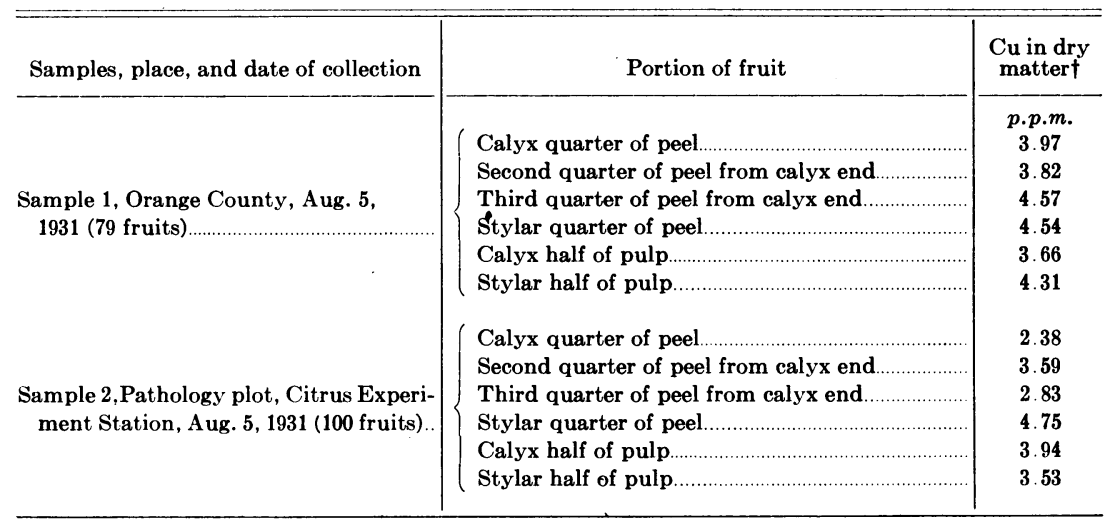

* Seed-free basis.

† Samples of dry matter averaged about 100 grams each.

peel and pulp was therefore made in subsequent determinations, and in some cases these were further subdivided, as shown in table 8. This method of dividing the fruit is an outgrowth resulting from the experiments of Haas and Klotz ${ }^{(19)}$ on gradients in the composition of citrus fruit.

Table 8 gives the results of copper determinations in various portions of healthy and diseased Valencia oranges. Samples 1 and 2 represent various aliquots of the dry matter of 79 and 100 Valencia oranges obtained from Orange and Riverside counties, respectively. Haas and Klotz $^{(19)}$ have tabulated the organic and inorganic contents, not including copper, of the portions mentioned in table 8. The results for copper in the present paper suggest a greater concentration of copper in the stylar than in the calyx portion of the peel in both samples.

Twenty-five fruits were used in preparing each of the remaining dried samples, data for which are given in table 9. Samples 1 and 2 were obtained in San Diego County. The data for these samples show that the exanthema-affected peel and pulp both contain smaller concentrations of copper than the corresponding portions of fruit from healthy trees. 


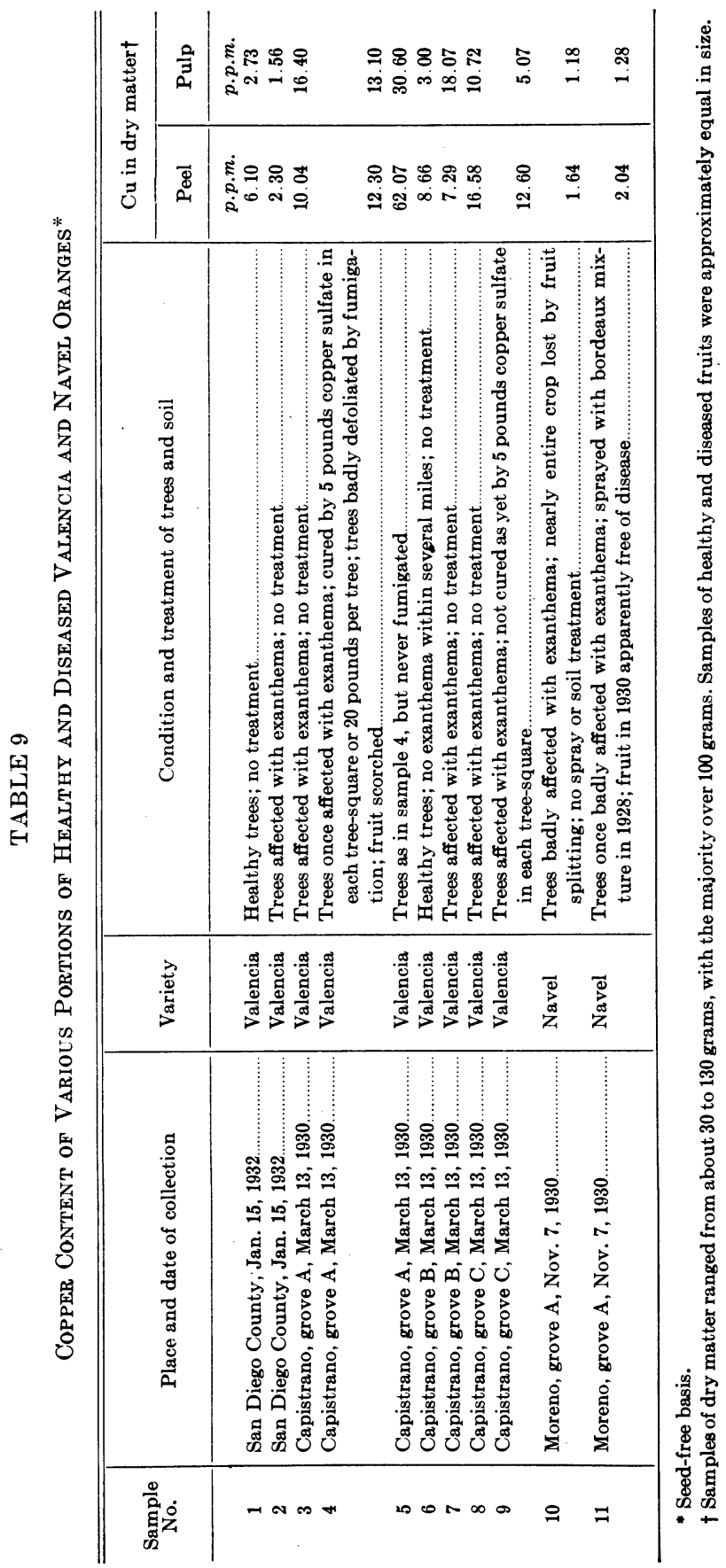


Samples 3, 4, and 5 were obtained on a different type of soil at Capistrano. Fruit (sample 3) from exanthema-affected trees that received no copper treatment contained less copper in the peel than the fruit from trees on copper-treated soil (samples 4 and 5). The peel of sample 4 showed only slightly more copper than sample 3 . This may be due to the defoliation of the trees by the fumigation, with reduced absorption as a result. Since the fruit was severely burned when fumigated, this may have checked the absorption of copper as compared with the fruit of sample 5, which was not fumigated and hence was not burned. Many of the most severely injured fruits had fallen prior to the collection of the fruit sample. It is possible that the fruits remaining on the trees contained less copper than those that had fallen. Experience has shown the peel to give more reliable results than the pulp of Valencia oranges from which the seeds have been removed on account of the variability in their number. The copper content of sample 7 shows a slightly reduced copper content in the peel of exanthema-affected fruit as compared with sample 6 .

Samples 8 and 9 were from badly diseased trees. Even though copper sulfate was used in the case of sample 9, the appearance of the trees and fruit, and the copper content of the peel, indicate that either sufficient time had not elapsed since the application of the copper sulfate to permit recovery or that recovery was not possible. Copper sulfate applied to soil may not benefit all exanthema-affected trees, owing to the lack of an adequate root system to enable recovery to take place.

Sample 11 shows only the slightest increase in copper content, even though the trees and fruit apparently were cured of all exanthema symptoms. These values for sample 11, as well as the other data in table 9 , show the great variation that exists in the copper content of fruit peel and pulp obtained from various locations and the advantages of separating the peel and pulp. The data further indicate the necessity of conservatism in drawing conclusions from such studies.

Additional data were secured regarding the soil bearing the trees, from which samples 10 and 11 were obtained. The $\mathrm{pH}$ of the first 6 inches of soil was 7.03, while that of the third foot was 7.30. In some locations where the exanthema was severe, it was possible to push a soil tube 6 feet into the soil by hand. Nitrate determinations of 1 to 5 water extracts of the dry soil showed 16 parts per million $\mathrm{NO}_{3}$ in the first foot, 21 parts per million in the second, 12 parts per million in the third, and 13 parts per million in the fourth. While these values for $\mathrm{NO}_{3}$ show an ample supply of nitrate, they do not show an excessive supply. This is in harmony with the conclusions of other investigators, namely, that nitrate of itself is not the cause of exanthema or mottle-leaf. 
The question frequently is asked, "Is it the copper remaining on the soil or the increased copper within the tree that brings about fumigation injury?" When copper sulfate is added to the soil, it may require several years before it has changed sufficiently so as to be unrecognizable to the

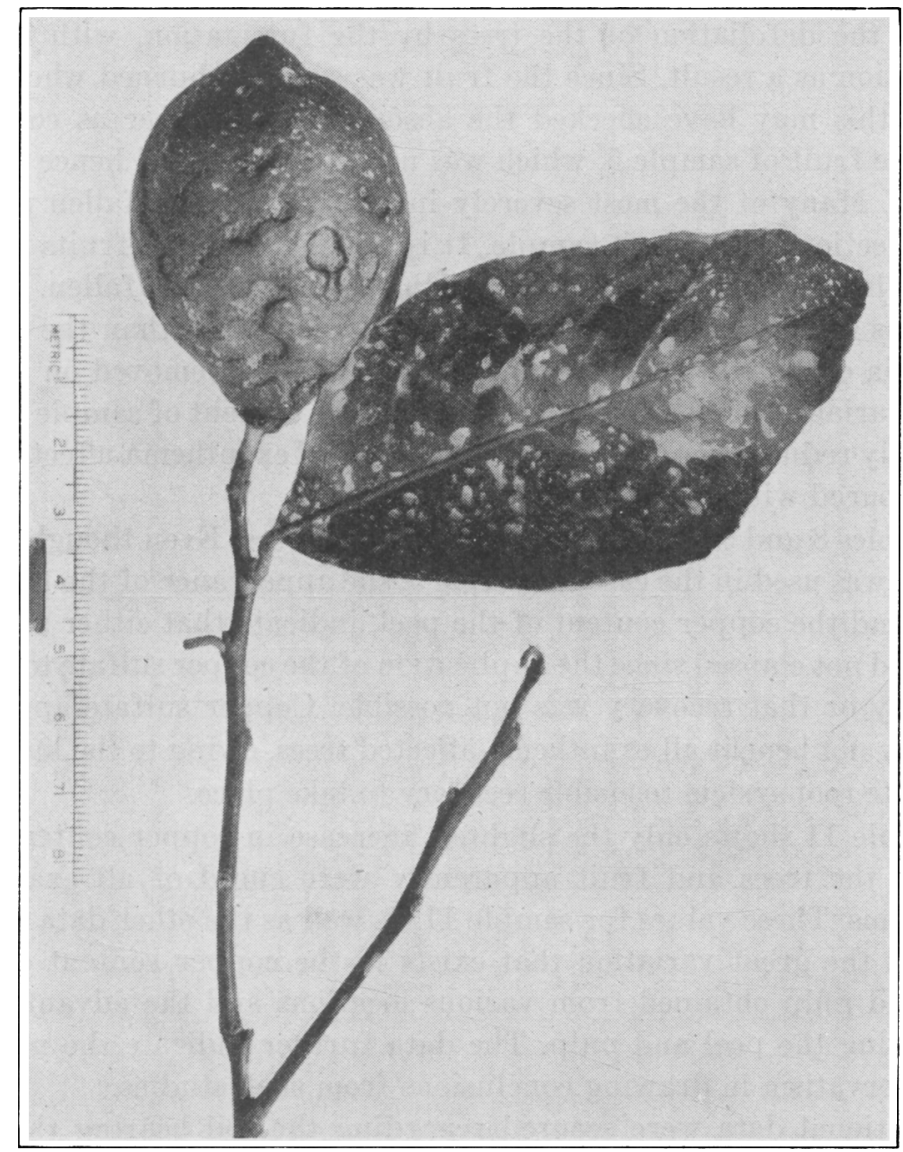

Fig. 2.-Lemon leaf and fruit (from tree of which the skirt was treated with bordeaux mixture for brown rot control) showing injury from the fumigation of a nearby lemon grove.

eye. (The finely pulverized form disappears more rapidly than the lumpy form.) After 3 to 5 years following the application of 5 pounds of copper sulfate to the soil, there should be very little, if any, soluble copper on the soil surface. The fact that fumigation injury frequently occurs after such a prolonged interval indicates the importance of the internal copper in the tree. Furthermore,. data have been presented which suggest that some trees that are injured year after year by fumi- 
gation may contain an increased content of copper in the leaves without copper having been intentionally applied.

Another aspect of the use of bordeaux mixture on the skirts (lower portion of crown) in the control of brown rot came to the attention of the authors in February, 1934. A lemon grove was fumigated without injury on the evening of the same day on which the skirts of a grove of lemon and orange trees on lower adjoining land were sprayed with

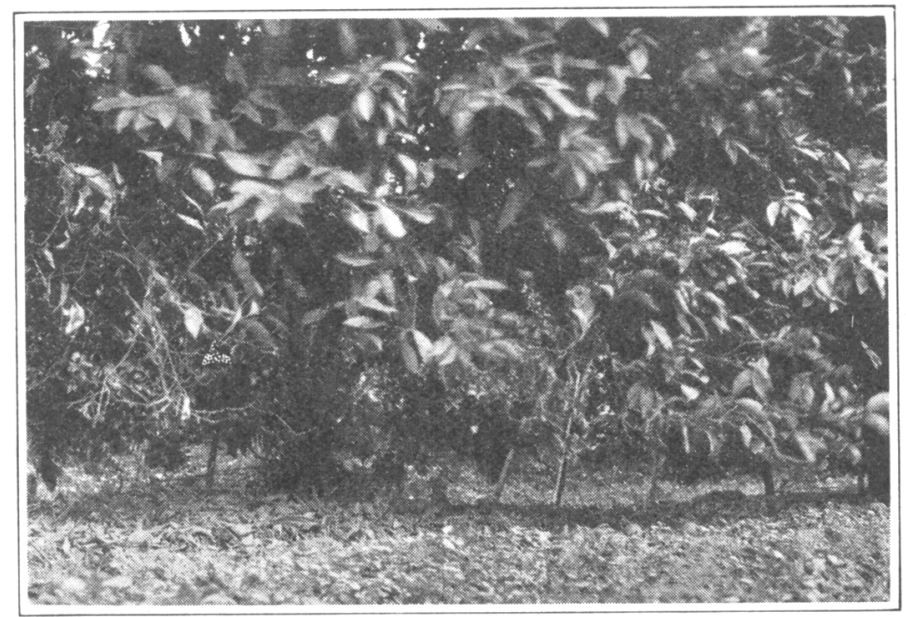

Fig. 3.-Lower part (skirt) of Navel orange tree injured when treatment with bordeaux mixture was followed within 24 hours by $\mathrm{HCN}$ fumigation in a nearby grove. Note the large number of dead leaves on the ground.

bordeaux mixture. Serious injury resulted to the latter. The fumigated grove was not only situated on higher land than the sprayed grove but was separated from it by a wide highway. The lower rows of sprayed trees were 8 in number and were planted at right angles to the highway. The sprayed trees were double-planted, there being about 45 lemon trees in the upper portion of the sprayed rows and about 28 Navel orange trees in the lower portion. The skirts of adjoining Navel orange trees were also sprayed with bordeaux mixture but subsequent to the fumigation of the lemon grove previously mentioned, and showed no injury.

Figure 2 shows the typical fumigation injury of the leaves and fruit of the skirts of the lemon trees sprayed with bordeaux mixture but to which the HCN from the fumigation of the lemon trees above the road may have drifted. Figure 3 gives some idea of the leaf fall following the injury to the Washington Navel orange trees also sprayed with bordeaux mixture. The effect of leaf abscission of the orange tree skirts in making the trees barren underneath when normally the crown of the trees 
extended to the ground, is seen beneath the white line in figure 4 . As the lemon grove above the road was fumigated, the gas may have drifted down the slope and injured the skirts of all of the trees in the rows. These rows consisted of 45 lemon trees at the upper end and 28 Wash-

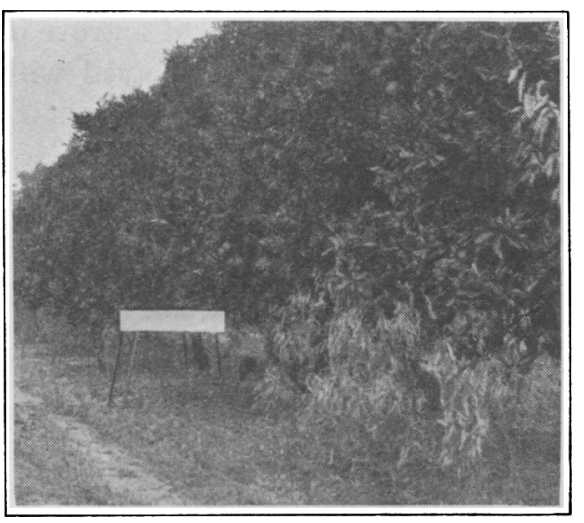

Fig. 4.-Navel orange trees severely injured when the lower part was sprayed with bordeaux mixture for brown rot control followed within a day by HCN from a fumigated lemon grove a considerable distance away on higher ground. Below the white line is seen the extent of defoliation of the skirts of the trees. ington Navel orange trees at the lower end. The degree of injury did not become smaller with increasing distance from the road but on the contrary was equally severe at any place in the rows of 73 trees each. Adjacent unsprayed Washington Navel orange trees facing the three sides of these 8 rows were not injured. The possibility exists that the injury of the trees may have been brought about because of the nature of the bordeaux mixture used without the action of an HCN drift, but this is unlikely in that the injury appeared to be typical of $\mathrm{HCN}$ and because trees sprayed after the fumigation were unaffected. However, the possibility is not excluded that the two lots of bordeaux mixture may have been different in composition.

If further cases are found to confirm this one as being due to the drift of HCN downhill with its injurious action upon foliage sprayed with bordeaux mixture, it would become of great importance to growers on sloping areas to know at all times precisely what their neighbors intend doing in order to avoid such HCN damage.

The owner of the grove from which samples 10 and 11 (table 9) were secured finds that in his various groves he may fumigate very soon (within 6 months) after using bordeaux mixture on the trees. Possibly this is due to the fact, as the data suggest, that his trees are somewhat deficient in copper.

It may be of interest here to compare the iron and copper content of citrus with that of other leaves and fruits. A comparison of the ratio of iron to copper in winter pears with that in other classes of foodstuffs was made by Moore, ${ }^{(2 \pi)}$ who found that the ratio for pears ranged from $0.523: 1$ to $0.755: 1$, while the ratios for four different classes of foodstuffs investigated by Peterson and Elvehjem ${ }^{(31)}$ and Lindow, Elvehjem, and Peterson ${ }^{(23)}$ as given by Moore ${ }^{(27)}$ ranged from $3.53: 1$ to $57.5: 1$. 
In table 1 the ratio for sample 1 (orange leaves) was about $50: 1$, that for sample 2 (lemon leaves), $21: 1$, and for sample 3 (lemon leaves), about $6: 1$. The ratios for grapefruit leaves in table 2 were as follows: Sample 1, 26:1; sample 2, 15:1; sample 3, 27:1; and sample 4, $16: 1$.

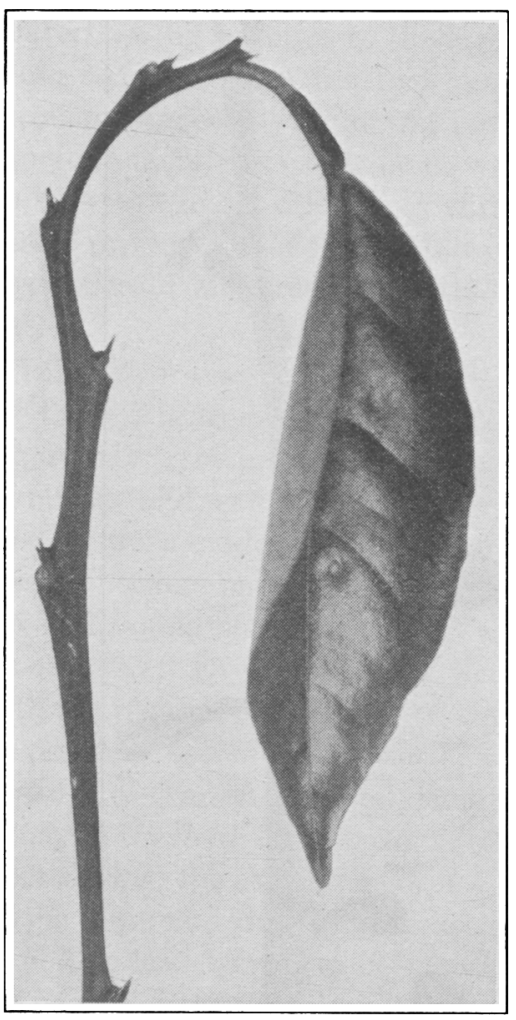

Fig. 5.-S-shaped shoots on Valencia orange trees affected with exanthema in sand cultures.

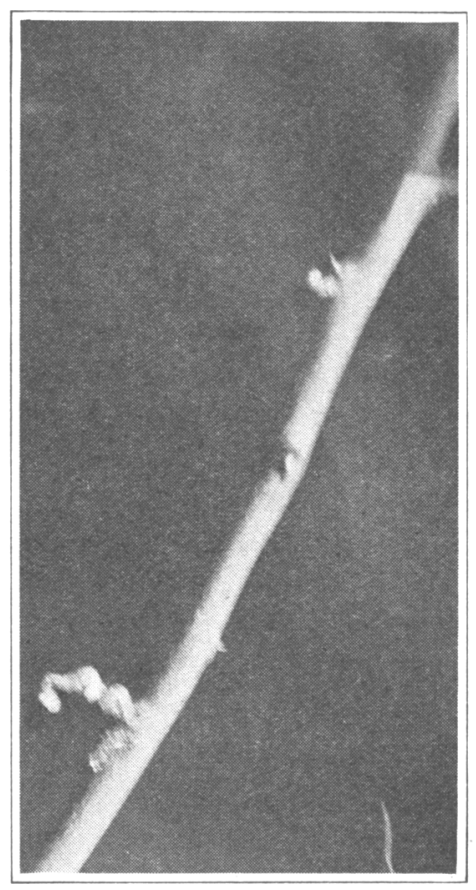

Fig. 6.-Gum exudation from Valencia orange twigs affected with exanthema. Note the killing of the terminal portion of the twig. The trees were grown in sand cultures.

Samples 2 and 4 were from trees growing on soil to which copper sulfate was applied, while samples 1 and 3 were from control trees. The copper nearly halved the ratio. In control Washington Navel orange leaves (table 4 , sample 3 ), the ratio was $22: 1$, while sample 3 from trees on copper-treated soil was only $16: 1$.

We have gained considerable chemical background with regard to the occurrence of copper in citrus, the relation of copper to exanthema in the field, and of injury by fumigation when copper is present in slight excess. We shall now consider a copper deficiency (under controlled conditions) as a cause of exanthema. 
On May 21, 1920, Valencia orange trees grafted on sour-orange stocks were planted, bare root, in 12 large tanks of pure silica sand. The tanks were 3 feet 8 inches in diameter by 4 feet deep. Below this the bottom

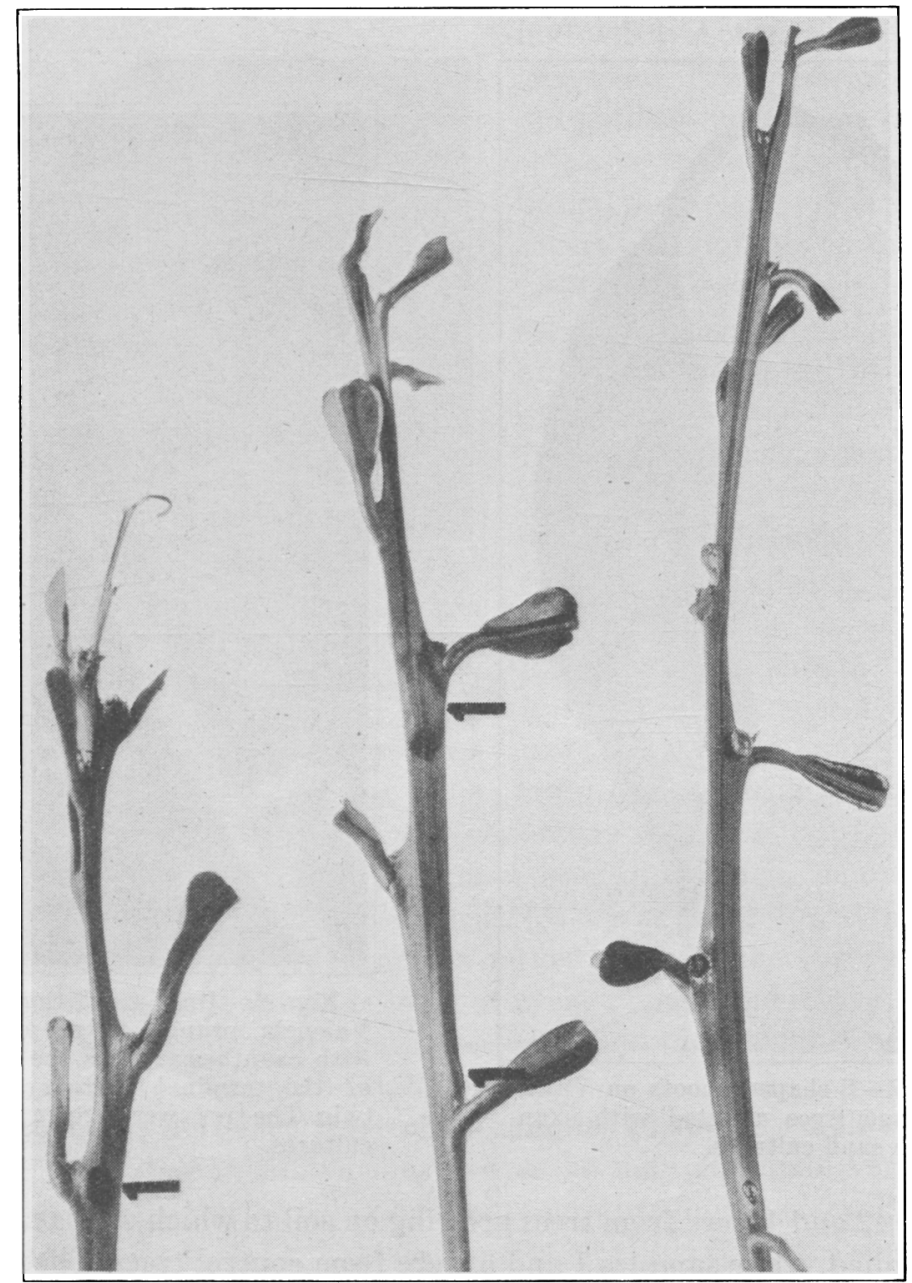

Fig. 7.-Exudation of gum from Valencia orange twigs affected with exanthema while growing in sand cultures. The unbroken gum pockets are marked in the photograph.

tapered 6 inches to a perforated plate beneath which was a 4-inch elbow that connected with a 2-inch galvanized iron pipe. Each tank had its individual drainage outlet in a trench. Crushed quartz rock was placed in the bottom of each tank as a drainage system for the sand. No organic matter was used except the small amounts of iron tartrate. 
The sand received a nutrient solution ( $\operatorname{Haas}^{(16)}$ ) including A-Z, which contained no added copper. The culture solution was mixed in large, paraffin-coated wooden barrels and generously supplied every few days to each of the tanks.

During the early growth in sand cultures no unusual symptoms appeared, owing perhaps to the large carryover of inorganic constituents from having grown for two years in soil. Until 1926 the trees were growing vigorously, and the indications were such that all we could conclude from this experiment was that citrus trees could be grown for many years in sand cultures without organic matter, even during the heavy production of fruit. However, in 1926 and succeeding years the large size of the trees permitted deficiencies to make themselves apparent.

In 1927 pronounced symptoms of exanthema appeared on several of the trees. Figure 5 shows the distorted or S-shaped appearance of many vigorously growing shoots. Many shoots began dying back from the terminus and exuding gum, as shown in figure 6. Gum pockets or blisters were evident on succulent shoots, as shown in figure 7. As the disease became more severe, a resinous excrescence (fig. 8) stained the affected young shoots, many of which died back, producing a witches' broom effect. Even the leaves were finally covered on the ventral side with the resinous stain (fig. 9). On some trees, many of the resin-stained leaves were becoming chlorotic, a result which is in harmony with the findings of Anderssen ${ }^{(2)}$ on deciduous trees suffering from copper deficiency in the field. Measurement of 100 leaves from healthy and diseased trees showed the average leaf of a healthy tree as being $3.9 \mathrm{~cm}$ wide and $7.8 \mathrm{~cm}$ long, and that of a diseased tree as being $3.7 \mathrm{~cm}$ wide and $9.7 \mathrm{~cm}$ long. The leaves tend to become narrower in proportion to the length.

The $\mathrm{pH}$ of the drainage water from the tanks ranged from 6.6 to 7.6, the nitrate from 351 to 1,226 parts per million, and the total solids 651 to 1,600 parts per million. The addition of 0.05 part per million of copper as sulfate to the culture solution gradually overcame the disease on all except one tree which, while not cured, was distinctly improved. While the use of copper sulfate was being tried, the studies were abruptly abandoned on July 1,1928 , because of the necessity of at once moving from the Rubidoux laboratory to the Citrus Experiment Station. This prevented further studies in getting at the facts surrounding this problem of exanthema and its relation to copper. Such tank experiments are expensive, of necessarily long duration, and require tedious and constant attention, because any one of many factors in a day may undo the work of years.

These tank experiments, together with field and laboratory work, 


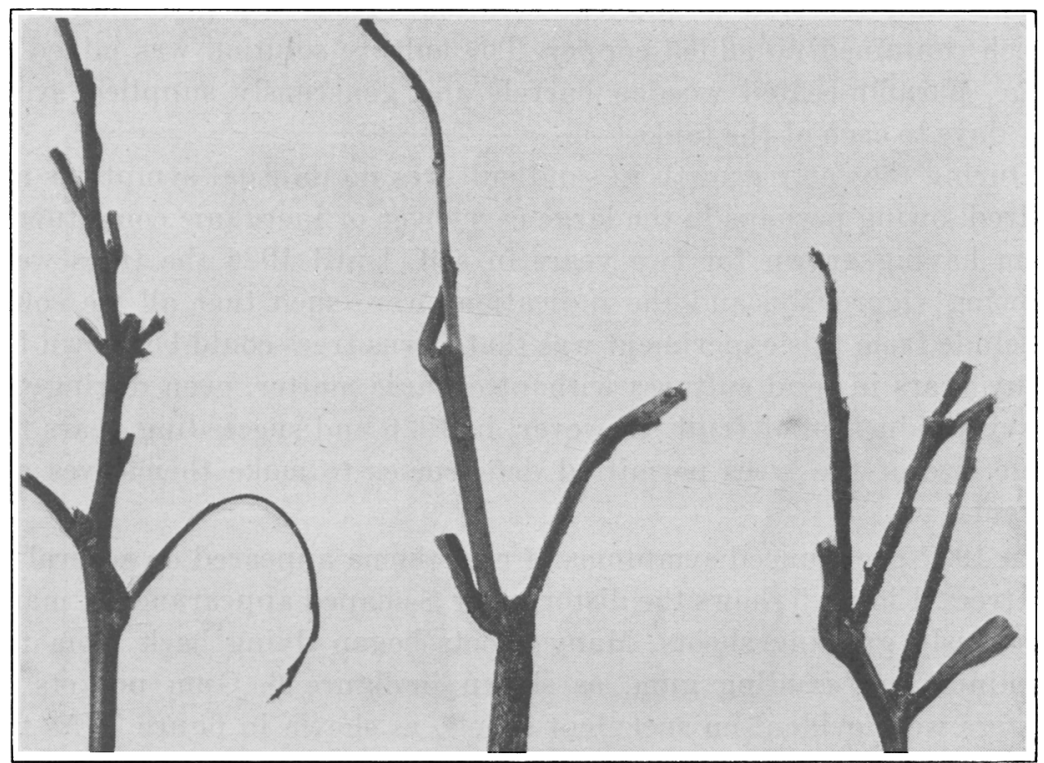

Fig. 8.-Resinous excrescence on young Valencia orange twigs from trees affected with exanthema in sand cultures.

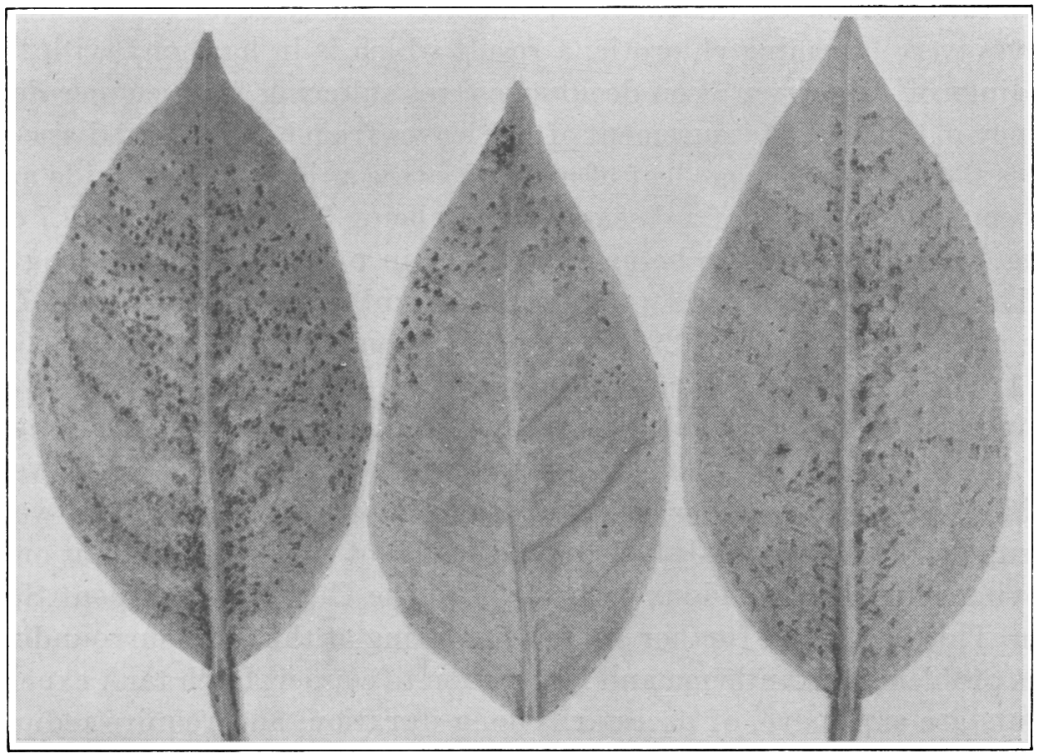

Fig. 9.-Resinous excrescence, particularly on the ventral surface of Valencia orange leaves affected with exanthema while the trees were grown in sand cultures. 
have shown minute amounts of copper as being essential for healthy growth in citrus, and that exanthema may be brought about by a deficiency in the supply or availability of the copper in the tree. No experiments have as yet been carried on in regard to the solubility of copper in citrus trees or in the soils in which the trees are grown. The results thus far indicate that the beneficial effects of copper sulfate came about by the correction of a deficiency of copper as such rather than by the precipitation of toxins or the killing of microörganisms. The amount of copper in a citrus tree that will still permit healthy growth seems to vary with other factors such as soil, climatic conditions, etc. Vigorously growing citrus trees in most cases withstand a considerable increase in the copper content of their tissues without injury unless fumigation enters in as another factor to be considered.

\section{SUMMARY}

A study was made of the copper content of citrus leaves and fruit by means of a method that permits of the accurate determination of minute amounts of copper.

The amount of copper required for healthy growth varies with the soil and climatic factors, although the solubility of the copper may later be found to be of considerable importance.

Small amounts of copper suffice to maintain healthy growth in citrus, although somewhat larger amounts appear to do no injury. For example, in a very sandy soil a single 125-pound application of copper sulfate to a large basin close to the drip of a grapefruit tree did not produce injury, although an application of $\mathbf{7 5}$ pounds to the soil close to another grapefruit tree brought about considerable injury. However, amounts of copper sulfate above 5 pounds per tree-square are to be used only in special cases, as they may cause injury on many soils, according to the nature of the soil and root distribution. For the control of exanthema, spraying with bordeaux mixture makes unnecessary the addition of copper sulfate to the soil.

Leaves of exanthema-affected trees show a reduced copper content. These results with citrus confirm those of Oserkowsky and Thomas ${ }^{(30)}$ on pears. The copper content of citrus fruit was best studied by analysis of the peel and pulp separately after removal of the seeds. Although more work is to be desired, the results thus far obtained for citrus indicate that a deficiency of copper occurs when the fruits are affected with exanthema.

It is very evident that exanthema can be readily controlled in the field by relatively small amounts of copper; but when the analytical data are examined there is considerable overlapping, and the clear, 
definite results that might be hoped for are not to be had. The results show rather clearly that considerable variation exists in the copper content of leaves and fruit from different localities and even different groves in a locality. Because of this, it appears that analyses for copper content will give little indication of whether or not a grove might be suffering from a lack of copper and on the verge of having exanthema or whether there may be so much copper present that HCN fumigation would likely result in injury. The importance of carefully chosen control leaves and fruit in work of this kind cannot be overemphasized.

By means of 12 large tank cultures filled with sand, typical symptoms of exanthema were produced : gum pockets and gum exudation appeared on vigorous shoots; a resinous excrescence was found on young twigs which died back and gave rise to short, new shoots that resembled a mild witches' broom effect; leaves were longer and narrower than on healthy trees; the ventral sides of diseased leaves were resin-stained; and the vigorous shoots of diseased trees made an S-shaped growth. During advanced stages of exanthema, many of the leaves became somewhat chlorotic, and their abscission followed.

Copper is essential for health in citrus, and when deficient, symptoms of exanthema make their appearance. When copper is used to correct exanthema, fumigation should not be practiced before sufficient time has elapsed until growth and reproduction, soil precipitation, and leaching have had time to reduce the somewhat too great an increase in the absorption of copper down to a concentration with which $\mathrm{HCN}$ will not react sufficiently to bring about injury.

Citrus trees that have year after year shown fumigation damage in comparison with trees in other groves were found to contain increased amounts of copper. However, the studies in this paper upon the relation of copper to fumigation injury should be regarded as preliminary. 


\section{LITERATURE CITED}

1 Aluison, R. V., O. C. Bryan, AND J. H. HunTer.

1927. The stimulation of plant response on the raw peat soils of the Florida Everglades through the use of copper sulphate and other chemicals. Florida Agr. Exp. Sta. Bul. 190:33-80.

2 Anderssen, F. G.

1932. Chlorosis of deciduous fruit trees due to a copper deficiency. Jour. Pomol. and Hort. Sci. 10:130-146.

3 Ansbacher, S., R. E. Remington, and F. B. Culp.

1931. Copper determination in organic matter. Ind. Eng. Chem., Analyt. Ed. 3: 314-317.

4 BUtlier, O., AND R. R. JENKINS.

1930. Effect on plants of cyanide fumigation following spraying with Bordeaux mixture. Phytopathology 20:419-429.

5 Cook, S. F.

1926. A latent period in the action of copper on respiration. Jour. Gen. Physiol. 9:631-650.

6 Cunningham, I. J.

1931. CXLI. Some biochemical and physiological aspects of copper in animal nutrition. Biochem. Jour. 25:1267-1294.

7 Elvehjem, C. A.

1932. The action of copper in iron metabolism. Sci. Proc. XXVI, Soc. Biol. Chem. In: Jour. Biol. Chem. 97:xvi-xvii.

8 ElvehJem, C. A., and E. B. Hart.

1926. Iron in nutrition. II. Quantitative methods for the determination of iron in biological materials. Jour. Biol. Chem. 67:43-51.

9 Elvehjem, C. A., H. Steenbock, and E. B. Hart.

1929. Is copper a constituent of the hemoglobin molecule? Jour. Biol. Chem. $83: 21-25$.

10 FAWCETT, H. S.

1914. Does bordeaux paste cause injury when followed by fumigation? California Dept. Agr. Monthly Bul. 3:41-43.

11 FawCETT, H. S., AND H. A. Lee.

1926. Citrus diseases and their control. 582 p. (See specifically p. 243-252; p. 501-503.) MeGraw-Hill Book Company, New York.

12 FLoyd, B. F.

1913. Experiments with citrus die-back. Florida Agr. Exp. Sta. Rept. 1912:102114.

13 FUdGe, B. R.

1931. Die-back of citrus. Florida Agr. Exp. Sta. Rept. 1931:57-58.

14 Guba, E. F.

1926. Injury to glasshouse plants from hydrocyanic acid gas, following the application of copper fungicides. Phytopathology 16:633-634. 
15 Guba, E. F., ANd E. B. Holland.

1933. Effect of hydrocyanic acid gas on cucumber plants previously sprayed with copper fungicides. Massachusetts Agr. Exp. Sta. Bul. 303:1-16.

16 HAAS, A. R. C.

1932. Some nutritional aspects in mottle-leaf and other physiological diseases of eitrus. Hilgardia $6(15): 483-559$.

17 HAAS, A. R. C.

1932. Injurious effects of manganese and iron deficiencies on the growth of citrus. Hilgardia 7(4):181-206.

18 HAAS, A. R. C.

1934. Relation between the chemical composition of citrus scale insects and their resistance to hydrocyanic acid fumigation. Jour. Agr. Research 49:477492.

19 HaAS, A. R. C., AND L. J. KLotz.

1935. Physiological gradients in citrus fruit. Hilgardia 9(3):181-217.

20 HART, LESLIE.

1932. Aluminum in ash of plant materials, fruit juices, and similar products. Jour. Assoc. Official Agr. Chem. 15:285-289.

21 JoSEPHS, H. W.

1932. Studies on iron metabolism and the influence of copper. Jour. Biol. Chem. 96:559-571.

22 Kelley, W. P., AND A. B. Cummins.

1920. Composition of normal and mottled citrus leaves. Jour. Agr. Research 20: 161-191.

23 Lindow, C. W., C. A. Elvehjem, and W. H. Peterson.

1929. The copper content of plant and animal foods. Jour. Biol. Chem. 82:465471.

24 Lipman, C. B.

1914. The poor nitrifying power of soils a possible cause of "die-back" (exanthema) in lemons. Science n.s. 39:728-730.

25 Lipman, C. B., AND G. MacKinney.

1931. Proof of the essential nature of copper for higher green plants. Plant Physiology 6:593-599.

26 MCCleery, F. C., AND W. B. StoKes.

1929. Control of exanthema of citrus in New Siuth Wales. Agr. Gaz. N. S. Wales $40: 523-534$.

27 MOORE, J. C.

1933. Biochemical investigations of certain winter pears. Oregon Agr. Exp. Sta. Bul. 316:1-10.

28 Myers, V. C., ANd H. H. Beard.

1931. Studies in the nutritional anemia of the rat. II. Influence of iron plus supplements of other inorganic elements upon blood regeneration. Jour. Biol. Chem. 94:89-110.

29 Orth, O. S., G. C. WiCKWire, AND W. E. Burge.

1984. Copper in relation to chlorophyl and hemoglobin formation. Science 79: 33-34. 
30 Oserkowsky, J., AND H. E. Thomas.

1933. Exanthema in pears and its relation to copper deficiency. Science 78:315316.

31 Peterson, W. H., and C. A. Elvehjem.

1928. The iron content of plant and animal foods. Jour. Biol. Chem. 78:215-223.

32 PiPER, C. S.

1931. The availability of manganese in the soil. Jour. Agr. Sci. 21:762-779.

33 Rhoads, A. S., ANd E. F. DeBusK.

1931. Diseases of citrus in Florida. Florida Agr. Exp. Sta. Bul. 229:1-213. (See specifically p. 138-150.)

34 Ruprecht, R. W., A. F. CAMp, J. R. Watson, and W. B. Tisdale.

1929. Plant pathology at the Florida Station. Florida Agr. Exp. Sta. Rept. $1929: 43,51,52,54,68-81,97-101$.

35 SCOTT, W. W.

1925. Standard methods of chemical analysis. 4 th ed. 2 vol. 898 p. (See specifically vol. 1, p. 193b.) 142 ill. 3 col. pl. D. Van Nostrand Co., New York.

36 Smith, R. E., AND H. E. Thomas.

1928. Copper sulfate as a remedy for exanthema in prunes, apples, pears, and olives. Phytopathology 18:449-454.

37 SOMMeR, A. L.

1931. Copper as an essential for plant growth. Plant Physiology 6:339-345.

38 Stevens, H. E.

1918. Florida citrus diseases. Florida Agr. Exp. Sta. Bul. 150:15-110.

39 Thомаs, H. E.

1931. The curing of exanthema by the injection of copper sulfate into the tree. (Abstract.) Phytopathology 21:995-996.

40 Titus, R. W., H. W. Cave, and J. S. Hughes.

1928. The manganese-copper-iron complex as a factor in hemoglobin building. Jour. Biol. Chem. $80: 565-570$.

41 Underhill, F. A., J. M. Orten, ANd R. C. Lewis.

1931. The inability of metals other than copper to supplement iron in curing the nutritional anemia of rats. Jour. Biol. Chem. 91:13-25.

42 W addeld, J., H. Steenbock, and E. B. Hart.

1929. Iron in nutrition $X$. The specificity of copper as a supplement to iron in the cure of nutritional anemia. Jour. Biol. Chem. 84:115-130.

43 Whitehead, T. H., AND H. S. MilleR.

1933. Shorter method for determining copper iodometrically. Ind. Eng. Chem., Analyt. Ed., 5:15-16.

44 Wilson, J. D., AND H. A. RunNels.

1933. Some effects of Bordeaux mixture on transpiration. Ohio Agr. Exp. Sta. Bimonthly Bul. 18:147-151.

45 Wilson, J. D., AND H. A. RunNels.

1934. Influence of Bordeaux mixture and an oil emulsion on water requirement. Ohio Agr. Exp. Sta. Bimonthly Bul. 19:21-28.

46 WogLum, R. S.

1932. Handbook of citrus insect control for 1932. California Fruit Growers Exchange Bul. 9:1-25. 